\title{
LA FIGURA DE LA VÍCTIMA
}

\section{GENEALOGÍA Y USOS ARGUMENTATIVOS}

\author{
THE FIGURE OF THE VICTIM \\ genealogy and argumentative uses
}

\author{
A FIGURA DA VÍTIMA \\ genealogia e usos argumentativos
}

\author{
Omar Alejandro Murad \\ (Universidad Argentina de la Empresa (UADE) \\ Consejo Nacional de Investigaciones \\ Científicas y Técnicas de Argentina) \\ muradoma@gmail.com
}

Recibido: 10/02/2020

Aprobado: 31/03/2020

\begin{abstract}
RESUMEN
En nuestros días la figura de la víctima gobierna una buena parte de las intervenciones públicas de colectivos e individuos que no solo se asocian con minorías o grupos subalternos, sino que también gobierna el discurso de instituciones, colectivos e individuos que tienen un lugar consolidado en el statu quo. Una mirada rápida sobre la cuestión descartaría el uso de esta figura como una estrategia para generar agencia, puesto que la víctima se caracteriza por su pasividad. Sin embargo, el caso es que su utilización en el espacio público habilita ciertas prerrogativas en el agente que la invoca, al mismo tiempo que lo coloca en una posición que no necesariamente se caracteriza por su pasividad, sino que, al contrario, la figura dota al agente de posibilidades de acción muy específicas. En particular, en este trabajo nos proponemos poner en discusión este punto de vista considerando algunos ejemplos de negacionismo en torno al carácter de la víctima en cuanto tal. La negación de la víctima a partir de la disputa de su posición por parte de sus victimarios nos pone sobre aviso de un tipo de intervención verbal que tiene como ámbito de discusión a la figura de marras. En este trabajo proponemos, por una parte, historizar esta figura a partir del trazado de su genealogía, utilizando como insumos teóricos los estudios de Rene Girard y, por la otra, analizar retóricamente algunos casos ejemplares en los que se hace visible el tipo de agencia que caracteriza su uso. Para ello, nos serviremos de ejemplos tomados de la literatura de la historia y de las ciencias sociales y del movimiento feminista.
\end{abstract}

Palabras clave: Víctima. Retórica. Negacionismo.

\section{ABSTRACT}

Nowadays, the figure of victim rules several public interventions of individuals and collectives that not only belong to minorities and subaltern groups, but also it rules institutional, collective and individual discourses, that have a consolidated place in the 
statu quo. A quick look over this issue discards using this figure as a strategy of agency due to a victim is characterized by its passivity. However, the case is that its use in the public space able to certain prerogatives in the agent that invokes it and, at same time, it puts him or her in a position that is not necessarily characterized by its passivity but, on the contrary, this figure endows to the agent with very specific possibilities of action. Specifically, in this work we propose put into question this point of view considering a few examples of negationism about the character of the victim in such. The negation of the victim through the means of disputing its position by its aggressor attracts our attention a kind of verbal intervention that uses the figure of the victim. In this work we propose, on the one hand, to historicize this figure making its genealogy based on Rene Girard's studies about sacrifice and, on the other hand, to analyze rhetorically a few exemplary cases that visibilizes the type of agency that characterize its use. To do that we take examples from history and social sciences literature and the feminism movement.

Keywords: Victim. Rhetoric. Negationism.

\section{RESUMO}

Em nossos dias, a figura da vítima governa boa parte das intervenções públicas de grupos e indivíduos que não apenas se associam a minorias ou grupos subordinados, mas também governa o discurso de instituições, grupos e indivíduos que têm um lugar consolidado no status quo Uma rápida olhada na questão excluiria o uso dessa figura como estratégia para gerar agência, uma vez que a vítima é caracterizada por sua passividade. No entanto, o caso é que seu uso no espaço público permite certas prerrogativas no agente que o invoca, enquanto o coloca em uma posição que não é necessariamente caracterizada por sua passividade, mas, pelo contrário, a figura confere agente de possibilidades de ação muito específicas. Em particular, neste trabalho, propomos discutir esse ponto de vista, considerando alguns exemplos de negação em relação ao caráter da vítima como tal. A negação da vítima da disputa de sua posição por seus autores nos alerta sobre um tipo de intervenção verbal que tem como espaço de discussão a figura de marras. Neste trabalho, propomos, por um lado, historiar essa figura a partir do traçado de sua genealogia, utilizando como entradas teóricas os estudos de René Girard e, por outro, analisar retoricamente alguns casos exemplares nos quais o tipo de agência que caracteriza seu uso se torna visível. Para isso, usaremos exemplos extraídos da literatura de história e ciências sociais e do movimento feminista.

Palavras-chave: Vítima. Retórica. Negação.

\section{Introducción}

Una manera de abordar el estudio de las ansiedades de una época, tanto pasada como presente, es escuchar el murmullo que reverbera como un ruido de fondo sin que, por eso mismo, le prestemos mayor atención. Aquello de lo que hablamos todo el tiempo y que nos hace hablar es un material de primer orden para delinear las formas que habitan nuestro presente. Así, por ejemplo, cualquiera que realice la búsqueda del término 'víctima' en Google encontrará miles de entradas que se ocupan de cuestiones que van desde las víctimas de tiroteos, robos, accidentes de tránsito, estafas, y otros eventos y acciones más o menos accidentales o intencionados, hasta los topoi más comunes de nuestra época sobre las víctimas del Holocausto, de la bomba atómica en Hiroshima y Nagasaki, civiles de Palestina, violencia de género, discriminación étnica, religiosa o sexual, abusos, entre muchas otras. Incluso se pueden hallar referencias a víctimas de maltrato aplicadas a diferentes animales. Las víctimas exceden el ámbito de lo humano. 
La heterogeneidad de las víctimas, la variedad de significados que alberga el uso del término 'víctima', y la apelación a esta figura en los más diversos debates y contextos discursivos: periodísticos, políticos, jurídicos, históricos y memorialísticos, siempre públicos, la convierten en una auténtica keyword de este tiempo. Vale la pena señalar que Raymond Williams no reconoce el término en sus Keywords de 1976 (1983). Y es notable también que, en la actual recuperación del proyecto de Williams por parte de la Universidad de Pittsburg, la entrada "victim” es señalada como una de las palabras más relevantes del debate público de las sociedades contemporáneas, porque liga las experiencias traumáticas de individuos o grupos con políticas públicas y de defensa de derechos, en el marco de amplias discusiones. Como esa misma entrada señala, en estas discusiones se ha criticado el uso del término "víctima” para los casos de abuso, o para caracterizar a diversos grupos minoritarios y se propone en su lugar el término "sobreviviente" que destaca la resiliencia del agente victimizado. El rechazo se basa en la idea de que la noción de "víctima” supondría un agente pasivo que dificulta la percepción de la agencia individual y colectiva y de esa manera obtura su empoderamiento. Con todo, este rechazo descuida el uso de la figura de la víctima como una acción argumentativa que produce efectos muy precisos de agenciamiento a partir de la redescripción de un ámbito de posibilidades de acción.

A excepción de quienes han padecido un accidente, es decir que han sufrido acciones o eventos no intencionados, en todos los casos restantes la invocación de la figura de la víctima siempre supone el padecimiento de una relación asimétrica de poder. Ese es el elemento diferencial que distingue a la víctima de cualquier otro tipo de relación. En algunos usos la figura es invocada para redescribir una situación, haciendo visible la asimetría entre quienes son dominados y quienes dominan. En estas ocasiones, la figura se vuelve un ámbito de disputa en sí mismo, puesto que los agentes identificados como víctimas son dotados de ciertas prerrogativas, mientras los victimarios adquieren ciertas responsabilidades por las consecuencias de sus actos. Sin embargo, este escenario ideal raras veces se da. Como ámbito de disputa, lo más común es que a la víctima, i.e., quien ha sufrido un daño como consecuencia de hallarse en una posición desventajosa dentro de una relación de poder, se le nieguen las prerrogativas que trae aparejada la figura a partir del uso de estrategias muy específicas de interacción verbal. Estas estrategias pueden ser identificadas como técnicas retóricas.

En lo que sigue nos interrogaremos por la utilización de esta figura en el espacio público. Nuestra hipótesis es que habilita ciertas prerrogativas en el agente que la invoca, al mismo tiempo que lo coloca en una posición que no necesariamente se caracteriza por su pasividad, sino que, al contrario, la invocación de esta figura dota al agente de posibilidades de acción muy específicas. Son estas posibilidades de agencia las que se ponen en juego de manera un tanto paradójica en las intervenciones verbales que tienen como objetivo la inversión de estas prerrogativas y el consecuente borramiento o, más bien, invisibilización de la relación asimétrica de poder que es la que en primer lugar hace posible la posición de la víctima. A esta invisibilización de la puede considerar una forma de negacionismo, puesto consiste justamente en negarle a la víctima su carácter como tal.

Por eso, la recurrente elección de esta figura para efectuar intervenciones públicas nos lleva a la pregunta sobre su funcionamiento y posibilidades de agencia. En este trabajo realizaremos las siguientes tareas: en primer lugar, historizaremos esta figura a partir del trazado de su genealogía atentos a los cambios en su dimensión normativa; en segundo lugar, analizaremos algunos casos testigo en los que se hace visible el tipo de agencia que caracteriza su uso. Para ello nos serviremos de ejemplos tomados de la literatura de la historia y de las ciencias sociales y de la crítica feminista.

El enfoque que vamos a adoptar es retórico y esto por varias razones: primero, porque la extensa tradición retórica, más larga incluso que la de la filosofía, provee de un vocabulario que permite analizar al lenguaje sin comprometerse con los objetos sobre los cuales versa dicho vocabulario. ${ }^{2}$

\footnotetext{
${ }^{2}$ El uso de un metalenguaje nos permite evitar la circularidad o petición de principio en la que incurriríamos si utilizamos en nuestro análisis los mismos términos o conceptos que estamos analizando. Parte del problema de analizar, por ejemplo, la figura de la "víctima", consiste en evitar su caracterización de antemano sobre cómo debería ser una víctima, y luego evaluar que tan cerca o lejos se halla de
} 
Segundo, este metalenguaje retórico desde siempre ha llamado la atención sobre los actos verbales, i.e., sobre el discurso considerado como una acción. Esto evita el engorroso trabajo de deslindar cuándo un acto verbal modifica algún aspecto del mundo o del comportamiento de los agentes respecto del mundo y cuándo no lo hace. Nos libra, por ejemplo, de la fatigosa distinción entre teoría y práctica. Desde un punto de vista retórico, decir y hacer son una y la misma cosa. Tercero, esto no lleva a la consideración de la imaginación y su capacidad de crear ficciones como la facultad humana de primer orden en función del conocimiento. La imaginación y sus ficciones no se oponen al conocimiento y la realidad, sino que éstas son un producto de aquellas (Blumenberg, 2018; Grassi, 1999; 2015; Frye; 1991; Kermode; 2000; Pepper, 1942). Finalmente, el análisis de las intervenciones verbales situadas, de situaciones retóricas, nos permite ver el modo en que las disputas verbales se sirven de un acervo tópico común que funge como fuente de argumentos, y en este caso, como una plataforma de distribuye posiciones dentro de un ámbito de relaciones de poder. ${ }^{3}$

\section{Genealogía de la figura de la víctima}

La figura de la víctima aparece primero como una figura narrativa, i.e., caracteriza lo que puede hacer un personaje, su agencia. Luego, puede ser analizada también según su estructura inmanente o esquema. En ambos casos, las figuras sirven tanto como fuentes para la invención de argumentos como insumos que permiten lograr un efecto estilístico. El modo en que las figuras se combinan atiende principalmente al auditorio al que están dirigidas y pretenden antes que nada lograr un efecto que es tanto cognitivo como práctico, i.e., procuran tanto transmitir conocimiento como modificar la conducta del auditorio. Analizaremos primero la etimología y la forma narrativa de esta figura y luego su esquema figurativo.

"Víctima" es una voz latina cuya etimología es imprecisa. Su significado alude al sacrificio de animales e incluso personas. Hay quienes la asocian a la misma raíz de victoria, siendo "víctima" quien es sacrificado como resultado de una derrota. Pero esta etimología popular tiene numerosos detractores y ciertamente parece más bien producto de un prejuicio que resultado del análisis filológico. Una etimología más cuidada la relaciona a una voz etrusca ligada al significado de "elegir" y "seleccionar" ofrendas a los dioses, asociada a su vez a la voz latina "vigere”, i.e., "ser honrado" o "vigoroso", que daría por resultado exactamente lo contrario a la etimología anterior, algo así como "lo que está en el más alto honor", es decir, "ser seleccionado para el sacrificio". También podría estar relacionada a la voz latina "vicis”, i.e., "giro” u "ocasión”, aludiendo al intercambio de ofrendas y dones con los dioses. En todos los casos, la víctima es lo que se ofrece en sacrificio a los dioses, y tiene un sinónimo en el término "hostia”.

En inglés, en castellano y en la mayoría de la lenguas romances el significado principal del término víctima es prácticamente el mismo, (1) "persona o animal sacrificado o destinado al sacrificio". ${ }^{4} \mathrm{La}$ Real Academia Española atestigua este significado desde la edición de $1780^{5}$ y la edición del 2001 recoge cinco acepciones, aparte de la mencionada que encabeza la lista: (2) "Persona que se expone u ofrece a un grave riesgo en obsequio de otra", (3) "Persona que padece daño por culpa ajena o por causa fortuita”, (4) "Persona que muere por culpa ajena o por accidente fortuito”, (5) "Quejarse

dicha definición el uso considerado. Esta estrategia analítica metalingüística es la que ha utilizado Hayden White en Metahistoria para analizar el lenguaje utilizado por los historiadores en sus escritos (White, 2010). A menudo esta estrategia se confunde con una dimensión teórica del análisis textual, y hasta cierto punto es lícito hacerlo (Partner y Foot, 2013: 1). Sin embargo, la introducción del término "teoría" implica siempre una dimensión práctica de la cual el primer distingo se halla escindido, lo que trae aparejado una serie de distinciones y aclaraciones que subtienden una concepción del lenguaje a la que no suscribimos. Por eso, la utilización de un metalenguaje basado en el léxico retórico nos exime de estas distinciones y aclaraciones que poco agregan a nuestro trabajo.

${ }^{3}$ El concepto de "relaciones de poder" lo tomamos de Michel Foucault, quien ha explicitado sus presupuestos en numerosos trabajos, por ejemplo en Vigilar y castigar (1998).

${ }^{4}$ En inglés desde finales del siglo XV se lo utiliza con el siguiente significado: "living creature killed and offered as a sacrifice to a deity or supernatural power, or in the performance of a religious rite", desde 1650 se atestigua el significado de un daño, tortura o muerte, infringida por otro, desde 1718 alude a quienes han sufrido desastres o accidentes y desde 1780 a quienes han padecido un engaño. Entrada victim en Online Etymology Dictionary, recuperado en: https://www.etymonline.com/word/victim\#etymonline_v_7770.

${ }^{5}$ Así aparece la entrada "víctima” en la edición de 1780: "La ofrenda viva, que se sacrifica y mata en el sacrificio". 
excesivamente buscando la compasión de los demás”. La acepción (3) recién aparece en la edición de 1925, mientras las acepciones (4) y (5) recién en la edición del 2001. ${ }^{6}$ Mientras las dos primeras recogen el sentido original del sacrificio, las últimas tres introducen las nociones de culpabilidad e inocencia, ambas relacionadas en el siglo XX con el lenguaje jurídico, en relación tanto con delitos simples como con genocidios y otras violaciones a los derechos humanos.

En este breve recorrido por diversas acepciones de la voz "victima" podemos advertir un desplazamiento semántico que, sin abandonar nunca el carácter digamos pasivo de quien es victimizado, poco a poco van ganando visibilidad ciertas atribuciones que le conciernen a la palabra, tales como su padecimiento gratuito y, más específicamente, la identificación genérica de aquel que le infringe dicho padecimiento (el victimario) como parte del significado del término de marras, con total independencia del atributo arcaico respecto del honor que ostenta la víctima al ser obsequiada a los dioses como ofrenda.

\subsection{La figura de la víctima en la narrativa}

Desde un punto de vista narrativo, la figura de la víctima aparece en casi todos los relatos míticos y en la literatura antigua en general. Por ejemplo, el héroe mítico o trágico a menudo es una víctima en el sentido arcaico de víctima propiciatoria o chivo expiatorio. Aquí la víctima funciona como un pharmakos, i.e., tiene la función ritual de conjurar todos los males de la sociedad a partir de su sacrificio. Como tal, es investida de ciertos rasgos que la hacen identificable, que la vuelven un objeto de persecución: puede ser un extranjero, tener malformaciones físicas o enfermedades, ostentar un rango social bajo, realizar transgresiones a los tabúes más comunes como la prohibición del incesto o el parricidio, etc. Como lo evidencia el caso de Edipo, en general la víctima propiciatoria ostenta no uno sino varios de estos rasgos. (Girard, 2002: 36 ss.) La víctima como pharmakos se halla uniformemente distribuida en toda la literatura antigua en la forma de mitos, tragedias, comedias, etc. No solo en la cultura occidental, sino también en la americana, asiática, africana, oriental y, en fin, mundial. Está presente en cosmogonías, en el teatro griego, en los relatos para el entretenimiento popular, el romance, la tragedia moderna, etc. El punto de vista de todas estas narrativas es, justamente, el del victimario. (Girard, 2002: 37) Lo importante de este primer momento de la víctima como pharmakos es la invisibilización del perseguidor, i.e., de la selección y articulación de los rasgos que identifican al chivo expiatorio. (Girard, 2002: 261) Por eso, no se problematiza en absoluto su inocencia o culpabilidad; al contrario, se asume que merece ser una víctima, alcanza con el reconocimiento de sus rasgos victimarios. Como ha señalado Nortroph Frye en relación con la tragedia antigua,

El pharmakos no es inocente ni culpable. Es inocente en el sentido de que lo que le acontece es mucho más grave que cualquier cosa que pudiese provocar lo que él haya hecho, como el escalador cuyo grito ocasiona la avalancha. Es culpable en el sentido de que es miembro de una sociedad culpable o habitante de un mundo en el que tales injusticias son parte inevitable de la existencia. Los dos hechos no llegan a juntarse, permanecen irónicamente aparte. El pharmakos, en resumidas cuentas, se encuentra en la situación de Job. Job puede defenderse contra la acusación de haber cometido algo que haga que su catástrofe sea moralmente inteligible; pero el éxito de su defensa la hace moralmente ininteligible (Frye, 1991: 64).

En sentido estricto, el punto de vista del perseguidor, al no problematizar moralmente la culpabilidad o no de la víctima, la da por sentada. Por eso, alcanza con mostrar lo rasgos que la hacen objeto de persecución. En la tragedia griega, por ejemplo, alcanza con el error o equivocación del héroe, hamartia, que pone en funcionamiento todo el mecanismo persecutorio. La víctima no tiene que hacer otra cosa que equivocarse en base a un desconocimiento sobre sí mismo y sobre las fuerzas a las que se enfrenta. Esto lo lleva a hacer lo que no puede, de manera que las consecuencias de sus acciones no

\footnotetext{
${ }^{6}$ Entrada “víctima”, Instituto de Investigación Rafael Lapesa de la Real Academia Española (2013): Mapa de diccionarios [en línea], Recuperado en http://web.frl.es/ntllet.
} 
son las que él espera. El resultado de las acciones del héroe es la transgresión del orden establecido por ejemplo, en Edipo matar a su padre y tener relaciones incestuosas con su madre- pero, al mismo tiempo, estas mismas acciones restauran, a partir del sacrificio del héroe, ese mismo orden. "El transgresor se vuelve restaurador -escribe Girard- e incluso en fundador del orden que ha transgredido, anticipadamente en cierto modo" (Girard, 2002: 60). El pharmakos se vuelve a un tiempo veneno y remedio como el pharmakon médico. Un ejemplo de transgresor-restaurador es Prometeo quien desobedece a Zeus y les obsequia el fuego a los hombres. Aunque es castigado por su transgresión, con esa misma acción funda también la cultura humana basada en la técnica. Otro ejemplo, esta vez tomado de la mitología azteca, es el de Nanauatzin, el dios purulento que se arrojó como ofrenda al fuego para convertirse luego en el sol (Girard, 2002: 80 ss.).

Esta frondosa literatura nos muestra que la víctima como pharmakos es a un tiempo aborrecida y venerada. (Girard, 2005: 103) Su situación no es retratada en términos de culpabilidad moral, sino que la fuerza de la figura radica en su capacidad de invertir las relaciones de daño o perjuicio entre los perseguidores y sus víctimas. Es la causa de ciertos males como la discordia, la enfermedad o la sequía, pero también su remedio. El punto de vista del perseguidor se hace presente allí donde se naturalizan los rasgos que autorizan algún tipo de violencia sobre el agente victimizado o sacrificado. Los relatos son portadores de una asimetría de poder entre la víctima y el victimario que oculta el acto selectivo del último reparando, en cambio, en ciertos rasgos que porta el agente seleccionado. Invisibiliza, pues, el poder que elige este o aquel agente como chivo expiatorio y lo hace colocando toda su atención sobre la víctima.

Girard encuentra en el mecanismo del chivo expiatorio un modelo arquetípico que sirve para conjurar la violencia, cuya fuerza es a un tiempo desestructurante de lo social, pues disuelve todas las jerarquías, pero también fundante de la sociedad, pues solo a partir del ritual del sacrificio se apacigua la violencia indiferenciada. De allí que considere que todas las religiones encuentran su nacimiento en esta violencia fundadora, y que los mitos son un modo privilegiado de recordarla y legitimarla. La religión y el mito se fundan en la violencia y el sacrificio la purga, paradójicamente, con violencia ritualizada. (Girard, 2005: 100).

Un segundo momento en la historia de esta figura está representado en los evangelios, en particular en la Pasión de Cristo. Varias veces señalan que los perseguidores “aborrecen sin causa”, y Jesús le pide a su Padre que los perdone pues "no saben lo que hacen” (Girard, 2002: 258; 265). En la lectura de Girard, la revelación no es otra cosa que la denuncia del mecanismo generador de mitos, del chivo expiatorio, que anida en el punto de vista de los perseguidores. La Pasión de Cristo expone bajo una luz racional este mecanismo sin conseguir, por eso mismo, crear otro mito. Es la primera gran desmitificación del punto de vista del perseguidor, nacida en "el mismo seno del universo perseguidor" (260). Esto se ve con claridad en el cambio semántico de términos clave como 'perseguir' o ‘testigo'. Señala Girard que

\footnotetext{
En el latín clásico ninguna connotación de injusticia va ligada a la persequi; el término significa simplemente: perseguir ante los tribunales. Fueron los apologistas cristianos, especialmente Lactancio y Tertuliano, quienes decantaron persecutio en el sentido moderno. Se trata de la idea muy poco romana de un aparato legal al servicio no de la justicia sino de la injusticia, sistemáticamente torcido por las distorsiones persecutorias. En griego, de igual manera, mártir significa testigo y es la influencia cristiana lo que hace evolucionar la palabra hacia el sentido actual de inocente perseguido, de víctima heroica de una violencia injusta (261).
}

Lo que cambia aquí es justamente el punto de vista bajo el cual se percibe a la víctima. En la relación víctima/victimario la tradición nos ha legado numerosos testimonios desde la perspectiva del segundo de estos términos, pero recién el cristianismo invierte esta relación, colocándola bajo la luz del primero. El punto de vista de las víctimas es el de su inocencia, su completa falta de responsabilidad, su no culpabilidad y, en fin, su denuncia de una falsa atribución causal: las víctimas no son responsables de los males que se les adjudican. Por eso, los evangelios señalan a Jesús como el paráclito, es decir, la voz griega de ad-vocatus, el que "habla en nombre de otro", el abogado universal que intercede por las víctimas inocentes (Girard, 2002: 269-270). En la narrativa evangélica se invierte 
el punto de vista del perseguidor y se asume el de las víctimas, perseguidas sin causa, pues son inocentes. Esta inversión ha dejado profundas huellas en la cultura, en el lenguaje, dotando de nuevas valencias, de nuevas propiedades y atribuciones a la figura de la víctima. Y al hacerlo la ha convertido en un ámbito verbal de disputa, en un auténtico topos contemporáneo.

Tal es así que, en el siglo XX, en el contexto de la victimología, una subdisciplina de la flamante criminología, en el topos de la víctima la inocencia se vuelve el baremo que permite evaluar si se trata de una víctima ideal, es decir auténtica, o no. Desde sus inicios, y al igual que otras áreas de los estudios en criminología, la victimología busca clasificar y tipificar los distintos casos en los que un agente que padece un delito o daño puede ser catalogado como víctima. Al hacerlo, subrepticiamente evalúa cuál es el grado de responsabilidad o culpabilidad (guilty) de la víctima en el delito que ha padecido. La idea rectora es que la víctima no solo es pasiva, sino también activa en el proceso de criminalización y de esta forma su rol es definido a partir de una interacción con el criminal (Moriarty: 2008, 23). Al igual que la idea lombrosiana de que algunos hombres "nacen criminales", von Hentig, uno de los fundadores de esta subdisciplina, sostenía que algunos hombres "nacen víctimas”. Así, los ancianos y los niños, los inmigrantes y las personas con problemas psicológicos o cognitivos, las minorías raciales y las personas de conductas promiscuas, entre otros agentes de "riesgo", son propensos a ser víctimas (Moriarty, 2008: 22). Además, es preciso notar que uno de los términos clave utilizados por la victimología para culpar a la víctima, “victim precipitation”, fue acuñado en 1958 por Marving Wolfang para describir los casos en que un agente se convierte en víctima como resultado de la comisión de un delito. Su discípulo, Mechanim Amir aplicó unos años más tarde la misma denominación para describir los casos de agresión sexual (Moriarty, 2008: 25-26). Pero entre uno y otro caso, se da una diferencia nodal, puesto que una persona que agrede a otra con un cuchillo y está dispuesta a matar puede convertirse a su vez en víctima de homicidio por parte del agredido. Y lo mismo le podría ocurrir a un ladrón que muere en ocasión de robo. Pero el concepto resulta inaplicable a una mujer que ha sufrido una violación, puesto que considerarla propensa a ser víctima bajo este esquema implicaría en primer lugar que intentaba violar, o dañar de alguna manera, a su agresor. Esta línea de argumentación, desarrollada por la naciente victimología, trafica el supuesto de que el daño ocasionado es susceptible de una responsabilidad compartida entre el agresor y la víctima. Y ciertamente el desarrollo posterior de la subdisciplina hasta nuestros días no se ha privado de este enfoque. ${ }^{7}$

\subsection{Análisis del esquema de la figura de la víctima}

Pasemos ahora brevemente al análisis del esquema de la figura de la víctima. Encontramos en ella una relación entre dos términos correlacionados a partir de una distancia, i.e., de una asimetría que señala la posición exacta de cada uno de los puntos conectados por dicha relación de presuposición recíproca. En esta presuposición anida el tropo de la metonimia, puesto que la mención de uno de ellos dispara inmediatamente su asociación con el otro término. Así, quién dice "víctima" dice siempre "victimario".

Además de la metonimia que asocia estos dos términos, en el esquema de esta figura opera el tropo de la ironía que los correlaciona a partir de la inversión de los valores de cada uno de los términos correlacionados. Las cualidades de un término presuponen lo opuesto en el otro término. Así, lo contrario de la víctima es el victimario; la víctima supone siempre un 'victimario' y viceversa. Para lograr el efecto de transvaloración o la realización de la transmutación de las propiedades de un término en el otro, la aparición de uno de ellos en el contexto de la figura de la víctima supone siempre

\footnotetext{
${ }^{7}$ Un ejemplo relativamente reciente es el caso de la presentación mediática y jurídica del femicidio de dos jóvenes argentinas ocurrido en Ecuador poniendo el foco en su carácter de "víctimas propiciatorias”, i.e., haciéndolas responsables de su carácter de víctimas. Julissa Mantilla (8 de marzo, 2016). Ius 360 "el estereotipo de la víctima propiciatoria”. Recuperado en https://ius360.com/columnas/elestereotipo-de-la-victima-propiciatoria2/ (consultado 25/01/20).
} 
la elisión de las cualidades invertidas del otro. En la afirmación "x es una víctima" está contenido "hay un victimario de $\mathrm{x"}$.

Este mecanismo hace posible la suspensión de los efectos de juzgar a x como víctima y pone el foco en determinar si efectivamente aplica o no la figura de víctima al juicio sobre la situación de x. Pasa inadvertidamente de nivel semántico, elevándose del objeto hablar sobre "la víctima x" hacia hablar sobre "hablar sobre x como víctima". En otros términos, se pasa de la figuración de una experiencia personal o vicaria, al lenguaje utilizado para caracterizar un tramo de experiencia personal o vicaria bajo la figura de víctima. Sobre todo, este desplazamiento de uno a otro nivel busca discutir la pertinencia de la aplicación local, singular e histórica, de la figura. Este giro es de suma importancia pues al volver sobre la figura como "figura”, cambia el contexto que hace posible su interpretación y de esa forma disputa la normatividad que anida en la relación asimétrica de poder que la constituye como tal. La piedra de toque utilizada para decidir si aplica o no la figura de la víctima es el criterio de "inocencia". La única víctima "real" es la víctima inocente. De allí que, en general, los argumentos para discutir la idoneidad o no de una víctima pongan el foco en socavar su inocencia.

Hasta el momento hemos detectado dos técnicas retóricas que hacen posible la inversión verbal del rol de la víctima, convirtiéndola en victimario, e inversamente, de victimario a víctima. La primera es la intervención dialéctica que hace uso de la antífrasis, una variante de la negación irónica, que consiste en aludir a las cualidades opuestas a las que posee un objeto (Beristáin, 1995: 271). En este caso, consiste en dos negaciones y una afirmación: "vos no sos la víctima, yo no soy el verdugo, vos sos el verdugo”. El efecto que se consigue con esta técnica no solo es la inversión de las cualidades de uno y otro término, sino también el cambio del contexto que estos suponen.

La otra técnica retórica utilizada para redescribir narrativamente evaluaciones morales invirtiendo su valor es la paradiástole (Skinner, 2007: 307 ss.). ${ }^{8}$ Aristóteles, Cicerón y Quintiliano llaman la atención sobre esta técnica que no consiste en la mera sustitución de un valor por su contrario, por ejemplo la valentía por cobardía, sino en asignarle al comportamiento real de un agente un carácter moral de signo contrario al que le adjudican nuestros adversarios dialécticos. Así, por ejemplo, señala Aristóteles,

Pero tanto para alabar como para vituperar conviene tomar también lo que está próximo a la realidad, como si se identificase con ello. Por ejemplo, representar al precavido como calculador e intrigante, al simple como bueno y al insensible como manso. Es decir, que siempre hay que atribuir a cada una de las cualidades semejantes según lo que más convenga. Por ejemplo, presentar al iracundo y al furioso como francos; y al arrogante, como de gran altura y distinción; a los que exceden en algo, como si poseyesen las virtudes correspondientes, al audaz como valeroso y al pródigo como liberal (Aristóteles, Retórica, 1367b).

Lo que consiguen ambas técnicas aplicadas a casos de redescripción de la figura de la víctima es el cuidadoso borramiento de la relación asimétrica de poder constitutiva de la figura. A diferencia de otras figuras, la víctima presupone siempre un contexto de desigualdad que la constituye y hace posible. Como hemos visto, en un primer momento, como chivo expiatorio esta relación asimétrica está prácticamente invisibilizada y el foco es colocado en el punto de vista de los perseguidores, de los victimarios. En un segundo momento, el punto de vista de la víctima invierte el juego de visibilidades y queda expuesto el problema moral de la inocencia de las víctimas. Una vez señalada la asimetría entre víctima y victimario, ya no se puede borrar de la figura. Pero en este punto la disputa se desplaza hacia la consideración misma de la inocencia que permitiría distribuir correctamente el juego de responsabilidades y prerrogativas que anidan en esa figura. La inocencia de la víctima señala

\footnotetext{
${ }^{8}$ A propósito de la paradiástole utilizada como una técnica de redescripción evaluativa de acciones y eventos, Skinner escribe: [...] "puede decirse que la esencia de la técnica consiste en reemplazar una descripción evaluativa dada con un término rival para que sirva para caracterizar la acción no menos plausiblemente, pero que sirva, al mismo tiempo, para colocarla bajo una luz moral de signo contrario. Uno busca así persuadir a su audiencia para que acepte la nueva descripción, y por consiguiente, para que adopte una nueva actitud hacia la acción en cuestión.” (Skinner, 2007: 308).
} 
directamente la responsabilidad moral del victimario, causante de un daño injustificado. Al mismo tiempo, habilita moralmente a la víctima a dar cuenta de su padecimiento, a decir su verdad. ${ }^{9}$

\title{
2. Análisis del uso de la figura en espacio público
}

En el libro ¿Cómo conversar con un fascista? Reflexiones sobre el autoritarismo de la vida cotidiana, Marcia Tiburi nos da algunos ejemplos sobre el uso abusivo de la figura de la víctima por parte de sectores conservadores propio de nuestros días. Por ejemplo, ella cuenta que

\begin{abstract}
Tiempo atrás, un diputado, conocido por una homofobia que expresaba de múltiples formas, apareció como quien "invertía el juego" del prejuicio que quien prejuzga recrea a cada instante, colocándose en la posición de alguien que sufría "heterofobia”. Desde su punto de vista, era una víctima de odio por ser un representante de la heterosexualidad en una sociedad en la que la homofobia es la regla. Sin embargo, y aún más grave, trataba de ocultar esa regla mediante una equiparación con algo con lo que no había comparación posible. Simplemente, intentaba que su acto tuviera varios efectos: el primero sería la disminución de la gravedad de su habitual gesto homofóbico; el segundo, la banalización de la homofobia, ya que, comparada con su contraria, sería algo en cuyo nombre las personas actúan de forma banal y, por tanto, natural. Finalmente, las víctimas de homofobia serían criminales al convertirse en heterófobos. Cambiando el lugar de la víctima, equiparando los crímenes y las víctimas, ya no tendríamos víctimas ni criminales, y el diputado, como criminal, resultaría ileso, habiendo conseguido, además, hacer caer sobre su víctima la condición de culpable (Tiburi, 2015: 63-64).
\end{abstract}

El pasaje es clarísimo en cuanto a la descripción y análisis del uso verbal espurio de la figura de la víctima. El uso de la antífrasis es transparente: con su intervención el diputado mentado niega primero ser un victimario, un perseguidor, luego niega que los perseguidos, los homosexuales, sean víctimas, y finalmente afirma ser él mismo víctima de discriminación. Quisiera destacar, además, la importancia de la inversión del lugar del victimario, en este caso el diputado homofóbico, por el lugar de la víctima, los homosexuales en una sociedad homofóbica. Lo que la autora señala como regla, la homofobia de la sociedad brasileña es invisibilizada por este uso de la figura de la víctima. El resultado es la equiparación de víctimas y victimarios y el borramiento de todas las responsabilidades que le atañen a unos y las prerrogativas de los otros. Y tal vez lo más importante, al hacerlo encuentra nuevos medios para perpetuar las relaciones de dominación existentes en dicha sociedad. Aquí la heteronormatividad es la matriz de relaciones de poder que queda perpetuada e invisibilizada con este uso de la figura de la víctima.

En nuestro país un caso ejemplar del uso político de la víctima inocente lo hallamos en el prólogo al Nunca Más escrito por Ernesto Sábato. El argumento general es que en la Argentina se libró una guerra entre dos fuerzas, dos demonios, que tuvieron como rehén a la sociedad argentina en su conjunto. Emilio Crenzel destaca que, en el programa televisivo del Nunca Más Sábato, refiriéndose a las desapariciones, declaró que

[...] esto no es un problema político, como se suele argüir, esto es un problema ético y religioso. Personalmente, creo que ha sido el reinado del demonio sobre la tierra”. Estos "actos demoníacos”, prosiguió, se cometieron "no ya contra los presuntos o reales culpables de algo, sino contra la inmensa mayoría de inocentes absolutos [...] (Crenzel, 2013: 7).

El tópico es conocido. La presunta "inocencia absoluta” de la sociedad argentina desliga automáticamente a la sociedad civil de cualquier responsabilidad. ${ }^{10}$ La guerrilla, en cambio, que

\footnotetext{
${ }^{9}$ Sobre el rol del testimonio de víctimas hay una frondosa literatura. En nuestra lectura seguimos las tesis de Verónica Tozzi en torno al estatus privilegiado del testimonio de las víctimas en término tanto epistémicos como morales y de la paradoja que conlleva el dar cuenta de eventos y experiencias indecibles y que, al mismo tiempo, requieren ser dichos. (Tozzi, 2012).

${ }^{10}$ Federico Lorenz en su libro Las guerras por Malvinas señala que "La juventud, entre los años setenta y ochenta, fue vista tanto como depositaria de los valores sagrados de la Patria como campo propicio para la propaganda subversiva. Un elemento central en los reclamos por parte de los familiares de los desaparecidos consistió en minar la base del argumento militar para su culpabilización: aquel que los involucraba en actividades "subversivas". Si para el Estado represor toda actividad partidaria, política y cultural era sinónimo de la subversión, las jóvenes víctimas debían estar libres de ese pecado. Al mismo tiempo, para resaltar los crímenes dictatoriales, y destacar
} 
comenzó con acciones subversivas no es inocente y, en consecuencia, por más que se caracterice como aberrantes las torturas y las desapariciones es, con todo, responsable. La estrategia argumentativa no solo invisibiliza la responsabilidad de los políticos, empresarios, Iglesia y sociedad civil en general, en la represión ilegal y las desapariciones, sino que además iguala en poder y responsabilidad a los militantes revolucionarios y a los militares profesionales que formaban parte del poder represivo del estado argentino. Invisibiliza, pues, la enorme asimetría entre unos y otros contendientes y los medios ilegales, que vulneran las garantías del estado de derecho, utilizados por los militares. Es natural, en consecuencia, que la alusión a la inocencia en el ámbito de discusión sobre la represión de la última dictadura tienda a ser percibida como una forma de despolitizar las acciones de los agentes involucrados y, en particular, de borrar la responsabilidad de los militares devenidos verdugos e, inversamente, de responsabilizar a los militantes revolucionarios de su propia victimización.

Un último ejemplo. Valentina Salvi realizó un estudio sobre las estrategias memorialistas del ejército argentino después de la sangrienta dictadura que protagonizó. El libro lleva el sugestivo título De vencedores a víctimas. Allí Salvi describe como en un primer momento la memoria institucional del ejército asumió su participación en lo que denominaba guerra sucia como un triunfo sobre la subversión. Sin embargo, desde finales de los años 90 del siglo pasado, la estrategia discursiva institucional dio un giro brusco. Lo militares pasaron de ser héroes de una guerra sucia a víctimas de la guerrilla. Escribe Salvi:

[...] la figura de las "víctimas militares" permitió a la fuerza poner de relieve determinados hechos, personas y periodos del pasado reciente y ocultar, minimizar y disimular otros para salir del ámbito cerrado de la memoria corporativa e ingresar a la escena pública con un discurso verosímil y disputar los sentidos sobre el pasado que se cristalizaron en los últimos veinticinco años en torno a la memoria de los desaparecidos. Por otro lado, la facultó a renovar su deteriorada imagen con nuevas justificaciones y argumentos sobre lo actuado, con el propósito de apuntar al fortalecimiento de una memoria interna de la institución y al reconocimiento de la sociedad y el Estado (Salvi, 2012: 64).

Como queda puesto en evidencia por el fragmento citado, la apelación a la figura de la víctima lejos de desagenciar al discurso institucional y a los militares en general, los dota de nuevos recursos argumentativos y justificaciones de su accionar. En este caso, a partir de la técnica de la paradiástole los militares logran articular una descripción corporativa de sí mismos como víctimas. Para eso, se apoyan, por una parte, en la narrativa humanitaria desarrollada por los organismos de derechos humanos y, por la otra, en eventos acaecidos cuya valencia transforman de una guerra contra la subversión en la que como agentes históricos se reconocen como héroes y mártires de la patria, a una guerra fratricida que los encuentra como una de las tantas víctimas de una guerra civil (Salvi, 2012: 206). En este caso, al igual que en el anterior, la responsabilidad por las acciones cometidas en el marco de la guerra fratricida se reparte entre ambos bandos. La ilusión es justamente que hay dos bandos y que están en igualdad de condiciones. De esta manera borran, o más bien, invisibilizan, sus responsabilidades repartiéndolas con la de las víctimas legítimas. Pero hay más. Los militares también reparten los derechos adquiridos por las víctimas a partir de sus padecimientos; corporativamente reclaman para sí las prerrogativas de las víctimas, sus derechos y reconocimiento público. Buscan de esta forma legitimar una institución desprestigiada por su accionar durante la dictadura. En suma, se sirven de esta estrategia de redescripción narrativa para disputar un ámbito simbólico y dotar a su causa de valores positivos. En otras palabras, su redescripción hace posible que se agencien de un ámbito de posibilidades de acción que se supone vedado para la contrafigura de la víctima, es decir, el victimario. 


\section{Conclusiones}

En este trabajo hemos realizado la genealogía de la figura de la víctima para mostrar el modo en que algunos de sus usos argumentativos hacen posible la agencia de aquellos que invocan esta figura para redescribir sus acciones. Para ello, hemos optado por un enfoque retórico, puesto que cristaliza la manera en que el lenguaje verbal es una forma de acción cuyos efectos son de la máxima relevancia cuando se trata de modificar la percepción de una situación o agente histórico, e influir en la manera en que otros agentes actúan y perciben el mundo. En este caso particular, hemos mostrado que la figura de la víctima, que de ordinario pasa por ser desagenciante y pasiva, es en realidad una fuente de argumentos que provee de agencias muy específicas a quienes la usan. En consecuencia, esta figura se vuelve un ámbito de disputa simbólica en sí misma. Hemos procurado también que nuestro análisis de algunos de los usos de esta figura de cuenta de su extendida utilización en los más diversos debates e intervenciones públicas.

Finalmente, hemos querido llamar la atención sobre el potencial negacionismo que anida en el uso frecuente de esta figura. Negacionismo que consiste en invisibilizar la posición subordinada de un agente inmerso en una relación de poder que es constitutiva de la figura de la víctima y de la cual han surgido las prerrogativas de quienes la invocan. Las dos técnicas identificadas para lograr la inversión de la relación víctima-victimario, y la consecuente invisibilización de la víctima real, nos permiten calibrar el alcance de las intervenciones verbales en la arena pública que invocan a la "víctima”, al mismo tiempo que nos alertan sobre los peligros que anidan en ella. Tal vez, lo que podría considerarse como una trampa en la invocación de la figura es que, para quien ha sufrido el daño físico y psíquico de ser objeto de los más diversos abusos, ser investido por ella significa también la obligación de dar cuenta una y otra vez del carácter de víctima frente a la disputa constante de los victimarios. Justamente porque la figura no es ni pasiva ni desagenciante, como una mirada ingenua podría considerar, es que la misma se vuelve un espacio de disputa atractivo para esta forma de negacionismo. Nuestra intención en este trabajo ha sido contribuir al análisis crítico del lenguaje utilizado para representar lo social, en la convicción de que la tarea de redescripción del mundo no llega nunca a un final y de que, por eso mismo, es preciso disponer de las herramientas de la crítica para dar las batallas por el sentido de las cosas munidos de sus frutos.

\section{Referencias}

Aristóteles (2019). El arte de la retórica. EUDEBA. Buenos Aires.

Beristáin, H. (1995). Diccionario de retórica y poética. Porrúa. México D.F.

Blumenberg, H. (2018). Paradigmas para una metaforología. Trotta. Madrid.

Crenzel, E. (2013). El prólogo del Nunca Más y la teoría de los dos demonios. Reflexiones sobre una representación de la violencia política en la Argentina. Contenciosa. Vol. 1 No 1. 1-19.

Fassin, D. (2016). La razón humanitaria. Prometeo. Buenos Aires.

Foucault, M. (1998). Vigilar y castigar. El nacimiento de la prisión. Siglo XXI. Buenos Aires.

Frye, N. (1991). Anatomía de la crítica. Monte Ávila editores. Venezuela.

Girard, R. (2002). El chivo expiatorio. Anagrama. Barcelona.

Girard, R. (2005). La violencia y lo sagrado. Anagrama. Barcelona.

Grassi, E. (1999). Vico y el humanismo: ensayos sobre Vico, Heidegger y la retórica. Anthropos editorial. Barcelona. 
Grassi, E. (2015). Retórica como filosofía: la tradición humanista. Anthropos editorial. Barcelona.

Julissa Mantilla (8 de marzo, 2016). El estereotipo de la "víctima propiciatoria”. Ius 360. Recuperado en https://ius360.com/columnas/el-estereotipo-de-la-victima-propiciatoria2/

Kermode, F. (2000). El sentido de un final. Gedisa. Barcelona.

Lorenz, F. (2006). Las guerras por Malvinas. Edhasa. Buenos Aires.

Moriarty, L. (2008). Controversies in Victimology. Mathew Bender \& Company. Newark.

Partner, N. \& Foot, S. (2013). Historical Theory. Sage Publication Ltd., Los Angeles-London.

Pepper, S. (1942). World Hypotheses. University of California Press. California.

Pitch, T. (2009). La sociedad de la prevención. Ad-Hoc editorial. Buenos Aires.

Salvi, V. (2012). De vencedores a víctimas. Memorias militares sobre el pasado reciente en la Argentina. Biblos. Buenos Aires.

Skinner, Q. (2007). Lenguaje, política e historia. Universidad Nacional de Quilmes. Bernal.

Tiburi, M. (2015). ¿Cómo conversar con un fascista? Reflexiones sobre al autoritarismo de la vida cotidiana. Akal. España.

Tozzi, V. (2012). The Epistemic and Moral Role of Testimony. History and Theory. Vol. 51. No. 1. 117.

Victim (s.f). En Online Etymology Dictionary. Recuperado de https://www.etymonline.com

Victim (s.f.). En Keyword project. Recuperado de http://keywords.pitt.edu/keywords_defined/victim.html

White, H. (2010). Metahistoria. La imaginación histórica del siglo XIX. FCE. México.

Williams, R. (1983). Keywords. A Vocabulary of Culture and Society. Segunda edición. Oxford University Press. New York. 